\title{
Principle of work in the process of digitization and reconstruction of model of belt buckle by photogrammetry and 3D computer design
}

\author{
Momchil Tachev ${ }^{1}$, Tihomir Dovramadjiev ${ }^{1}$, Ginka Jecheva ${ }^{1}$ and Kremena Cankova ${ }^{1}$ \\ 1-Technical University of Varna, Department of Industrial Design, 9010, 1 Studentska Street, Varna, Bulgaria \\ Corresponding author contact: m_tachevetu-varna.bg
}

\begin{abstract}
Bulgarian female folk costume is rich in multiple characters, elements and details. One of the most characteristic is the belt buckles. As well as specially designed symbolism, the belt buckle - with their unique identity belong to the national - historical heritage of Bulgaria. In the present study a model of a belt buckle is digitized and reconstructed, and possessing grace and beauty. The realization of the completed three-dimensional computer model goes through stages of photogrammetry and computer design with special sculpting tools.
\end{abstract}

Keywords: Culture, history, digitization, photogrammetry, 3D

\section{Introduction}

With regard to women's folk costume, some of the most remarkable accessories are the belt buckles. In addition to its purely functional accessory (joining the edges of the belt and holding the woman's waist), they are characterized by their beauty in details and symbols (Georgieva I. (1993), Dimitrov P.(2012), NarodniNosii (2017) - o.s., NarodniNosii. (2018) - o.s, Tachev M. (2012)). Often they are made of expensive materials that include gold, silver and other precious metals and alloys. They are also specially inlaid and richly decorated with other valuable materials such as nacre, color enamel and semi-precious stones (Iliev I., Kazakova R., Genova M. (2014), Omda - o.s., RIM Shumen. - o.s., Sirakov N., Demirev V., Ilieva D., Ivanov I. (2014), Topalova R., Uchiteli (2016) o.s.). The belt buckles can also be seen as they are miniature artworks. This makes them models with distinctive national and historical value. In order to be preserved and preserved as such, it is not enough just to keep them in special places, museums and collections, but to digitize their geometry with all the details and elements. The digitization of the belt buckles enables them to be reproduced in real life if necessary, by $3 \mathrm{D}$ printing and to use virtual museums, interactive applications, presentations and more. One of the successful methods for digitizing models from real is photogrammetry (Lobanov A. N. (1984), Nazarov A. S. (2006), Obiralov A. I., Limonov A. N., Gavrilova L. A. (2002), Schenk T. (2005), Waas M., ZellD. (2014)).

\section{Materials and Methods}

The present work aims to develop a 3D digitized model of the belt buckle by means of photogrammetry. The photogrammetric process contains different stages and technical means, and for different parameters, different technical devices, recording equipment and software for the same purpose can be used, but with different manufacturers and developers at the choice of the specialists and the available material and technical base (Dovramadjiev T. (2017), Geodetic Systemso.s.,IQLaser-o.s.,Kaufman J., Rennie A., Clement M. (2015), LaaksoA. (2016)). 
For the realization of the model, the present study uses the principle of operation comprising the steps shown in fig. 1.
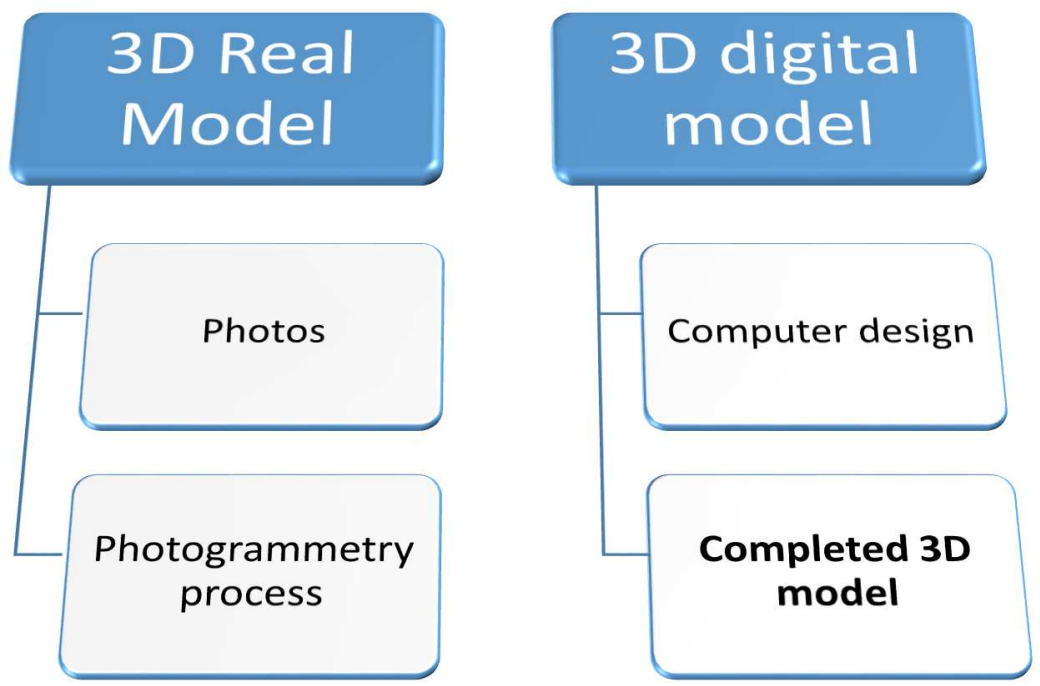

Fig. 1. Photogrammetric principle of work and computer reconstruction.

The model of the buckle to be digitized is shown in fig. 2 .

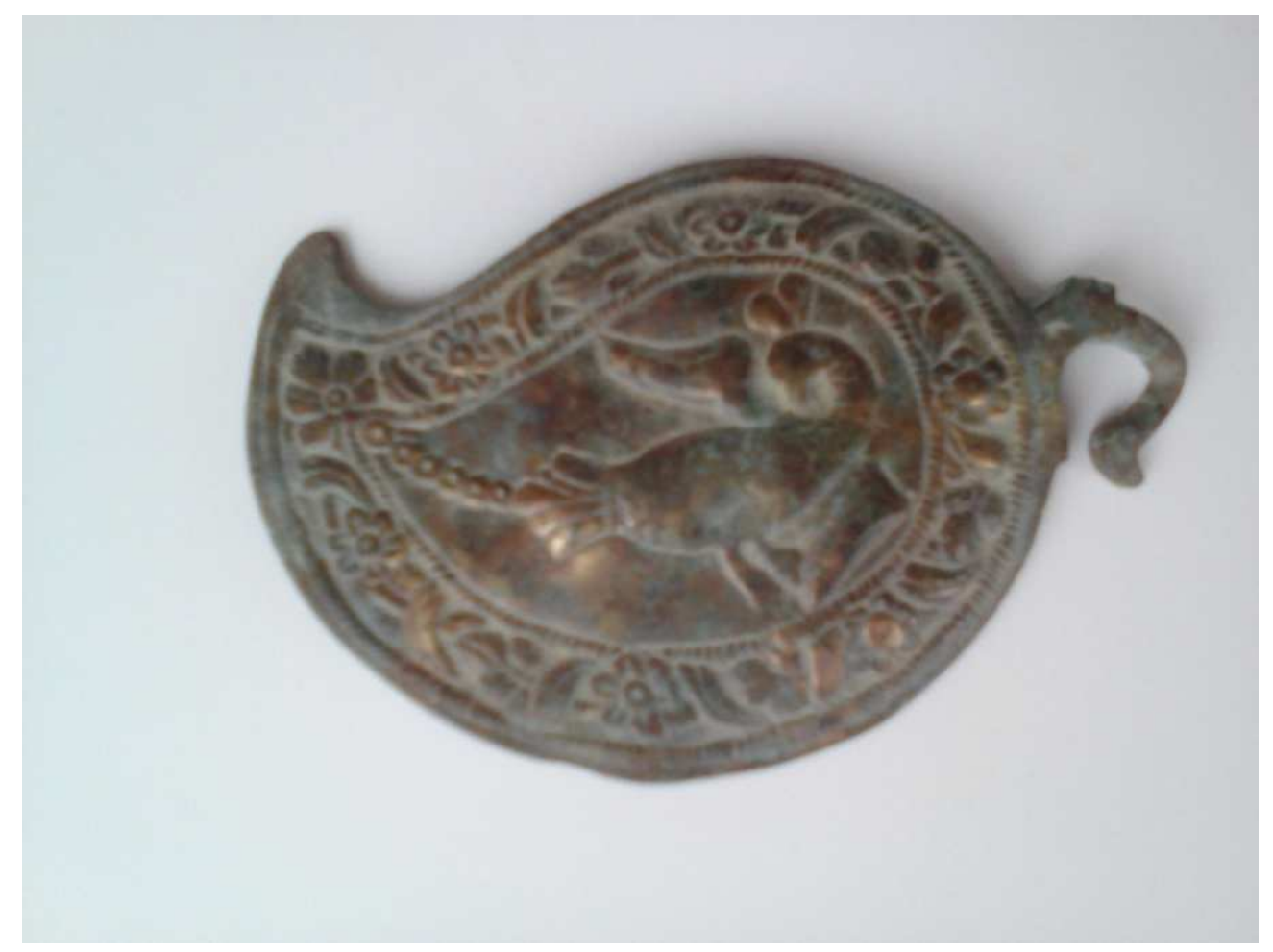

Fig. 2. Model of a belt buckle with floral motives and a bird. 


\section{Technical realization}

Digitization of the specimen requires proper compliance with the operating procedures for each of the working steps which include:

- Capture the real model of the buckle in a suitable setting including scene and light;

- Integration of received photos into specialized photogrammetric software. Autodesk ReCAP software (Autodesk ReCap -o.s.) is used;

- Defining the parameters of the photogrammetric calculation and obtaining the original 3D data;

- Export to specialized 3D geometry processing software. Autodesk MeshMixer software (Autodesk MeshMixer) is used;

- Reconstruction of the model. Sculpting tools and other operations are manually applied;

- Receiving a complete 3D digital model.

\subsection{Capture and integrate the photos in Autodesk ReCap photogrammetry software}

The capture of the model is conventional and pictures taken are with a total number of 50 . The photos are integrated into Autodesk ReCAP photogrammetry software (fig. 3).

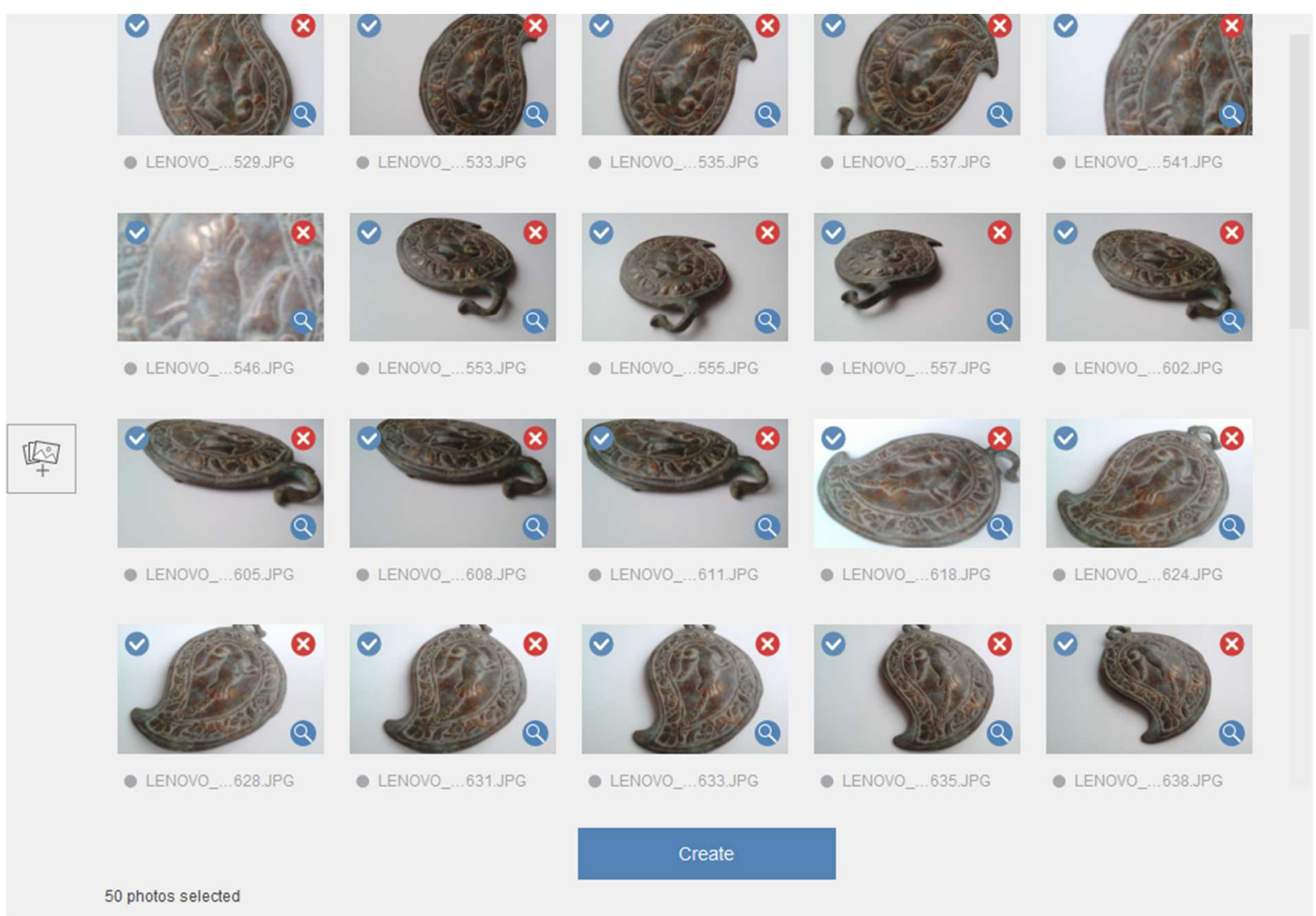

Fig. 3. Integrate the received photos (total 50) in Autodesk ReCAP photogrammetry software.

As a result of the computational process in Autodesk ReCAP, the following geometric data was visualized in the corresponding form (fig. 4). 


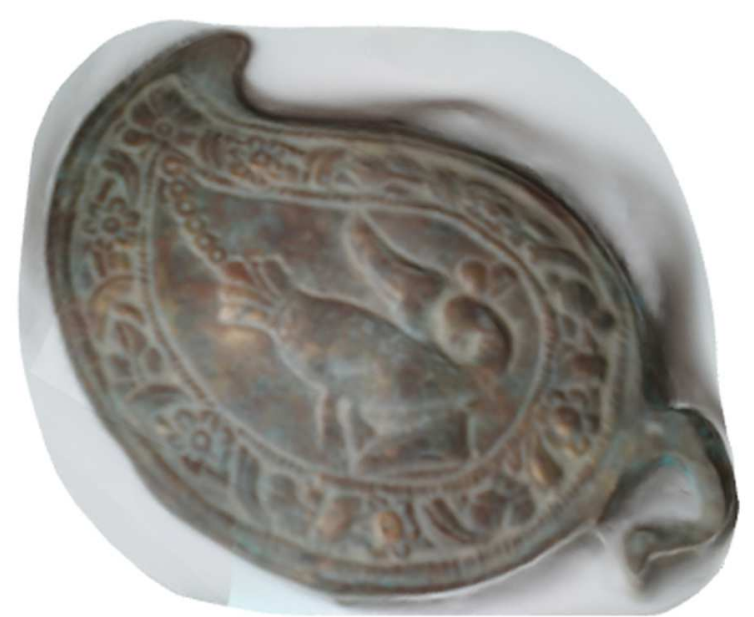

(a)

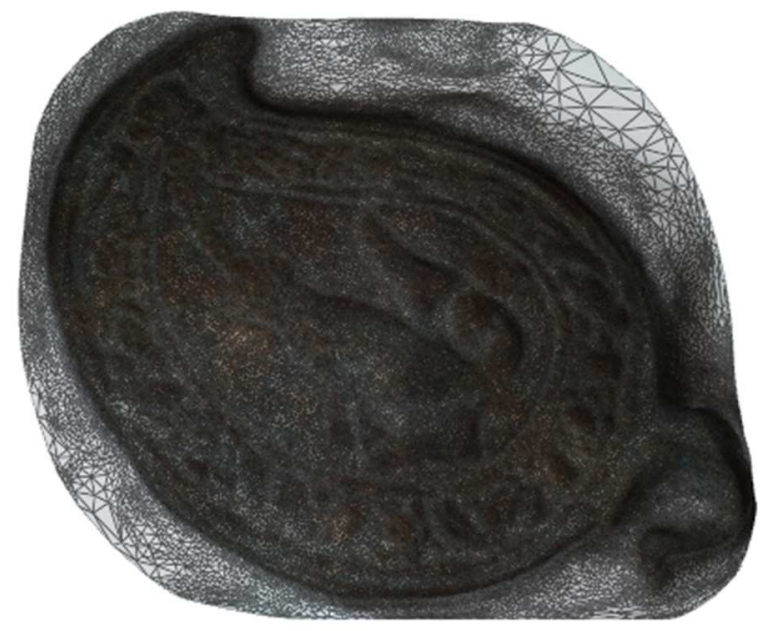

(c)

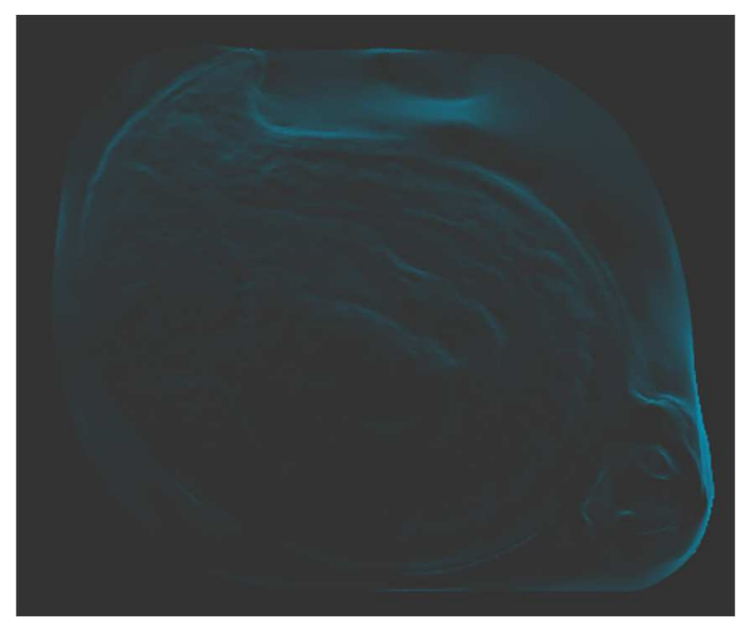

(b)

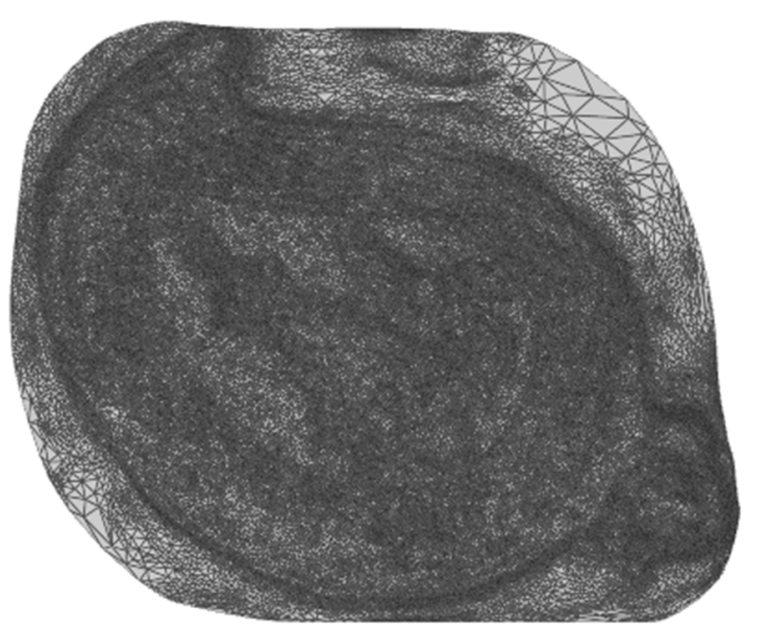

(d)

Fig. 4. Digital model of a belt buckle in Autodesk ReCAP environment: (a) Textured; (b) X-Ray; (c) Textured with wireframe; (d) Solid with wireframe.

From the initial results of 3D geometric data, it is evident that the model has to be reconstructed by optimizing the mesh. Therefore, it is necessary to use sculpting tools that are somewhat more convenient than conventional mesh modeling. Choosing the right software is of great importance, and one of the current good variants is Autodesk MeshMixer software.

The resulting 3D model in Autodesk ReCAP is exported to *.OBJ file format (also available in *.STL) for post processing with AutoDesk MeshMixer software.

\subsection{Working in Autodesk MeshMixer software. Optimize the mesh.}

Fig. 5 shows the imported model of the belt buckle (before starting the reconstruction process) and having the following mesh characteristics: Vertices: 82202 and Triangles: 164182. 


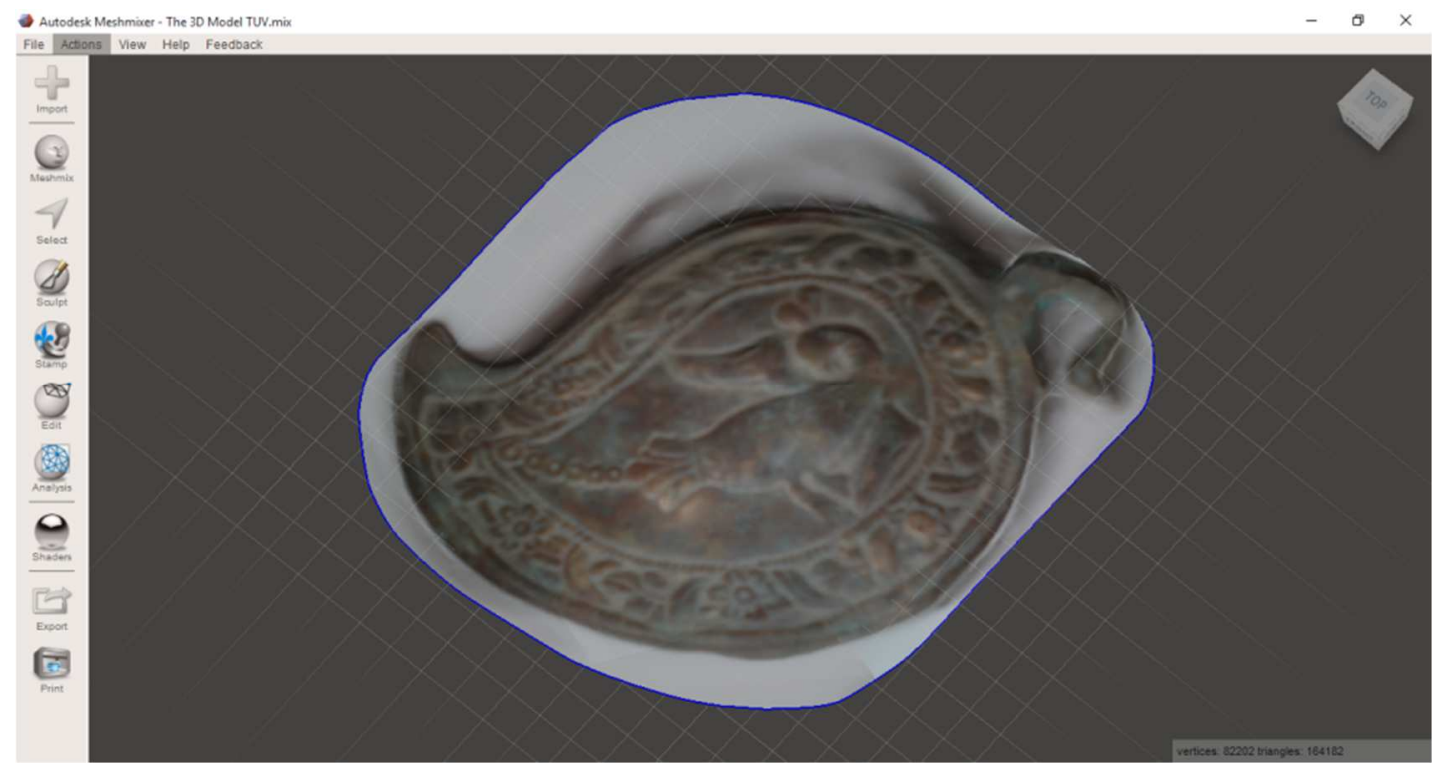

Fig. 5. The 3D model of belt buckles.

The zones (in orange - fig.6 (a)) to be removed from the main screen (Figure 6 (b)) are marked by manual selection. After the "cleaning" (fig.6 (c)) it is necessary to smooth out the outer edges (fig.6 (d)).

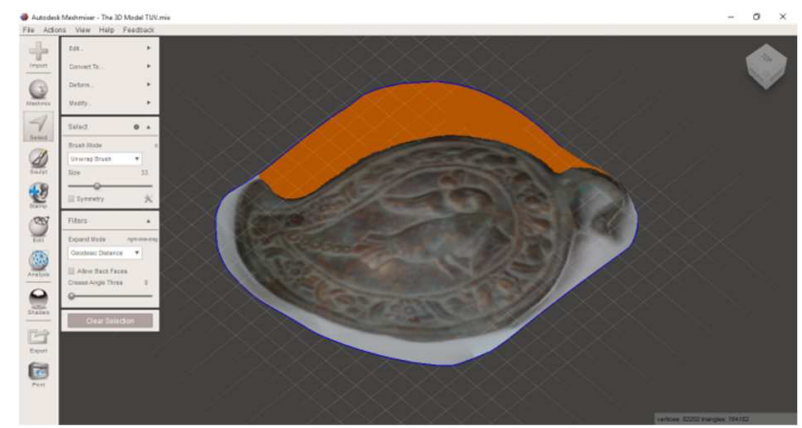

(a)

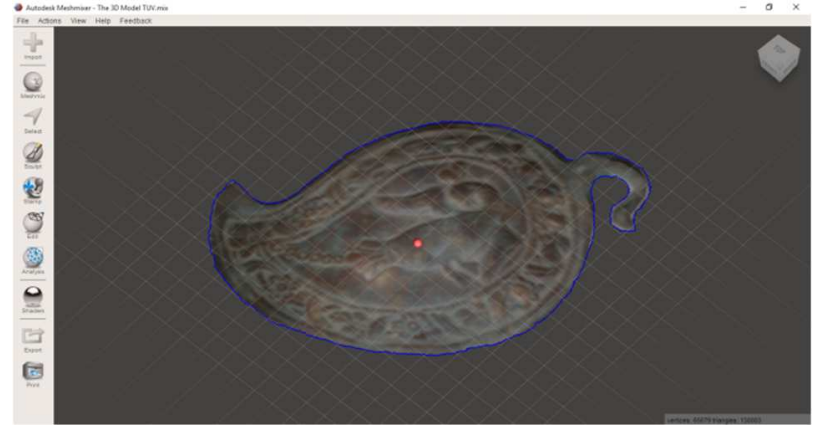

(c)

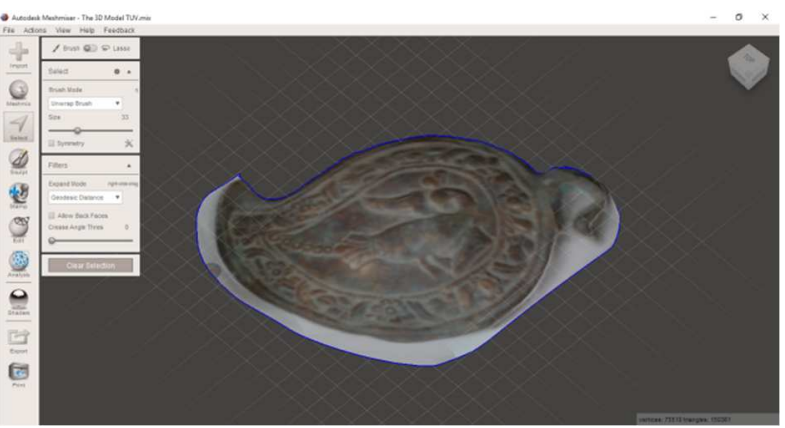

(b)

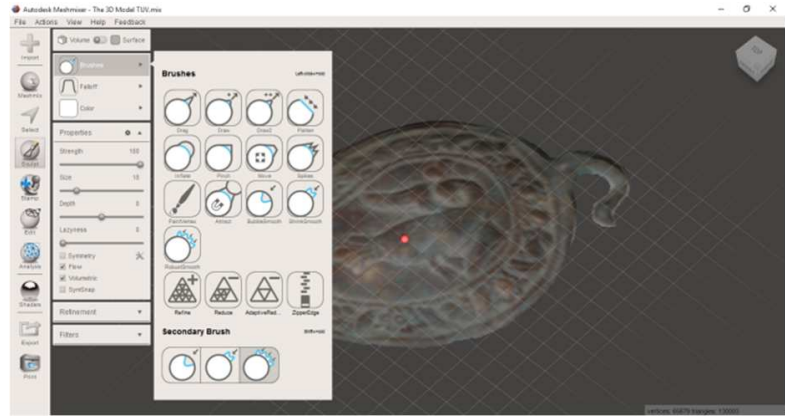

(d)

Fig. 6. Optimize the geometry of the model's mesh: (a) Select Brush (Brush Mode: Unwrap Brush + Size); (b) Remove; (c) Immediate position after trimming; (d) smooth out the mesh's outer mesh (Sculpt, Brushes /

SchrinkSmooth). 
The completed belt buckle model is shown in Fig. 7. The mesh consists of: Vertices: 63927 and Triangles: 126499.

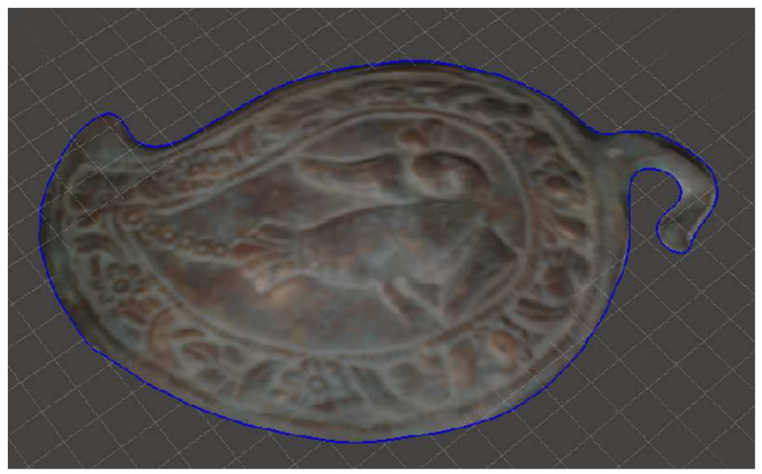

(a)

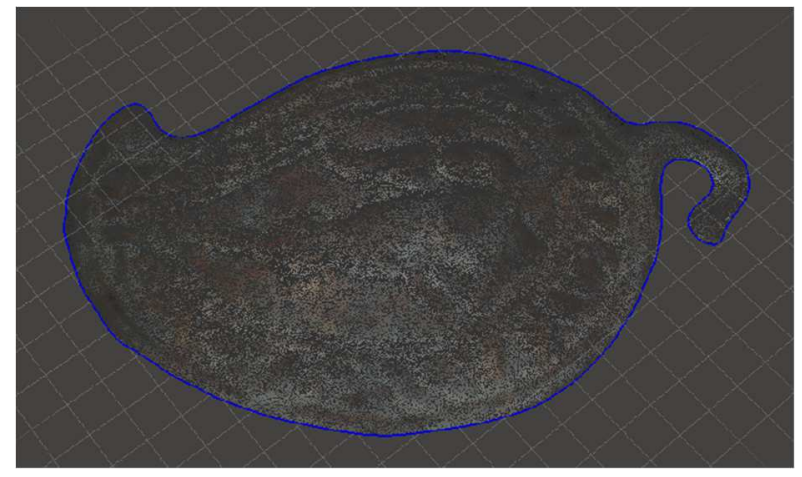

(b)

Fig. 7. Completed model of a belt buckle: (a) mesh textured; (b) mesh textured + wireframe.

\section{Conclusion}

In the present work a process of work is introduced involving photogrammetry and applicable software systems, facilitating the digitization and reconstruction of a model of belt buckle. The realization of this model is of particular importance in terms of its national-historical value. Based on this study, three-dimensional and other similar models can be digitized, giving different possibilities for further activity and realization. Such can be: creating a database that stores the 3D geometry of a similar type of samples; building concepts for multimedia presentation of national and cultural models; playback, etc.

Acknowledgments. The described work is a part of project KD-5 - 2018 / TUV "Study of photogrammetric possibilities and 3D digitization of models, objects, sculptures and monuments of national historical value".

\section{References}

Dimitrov, P. (2012). Metal decorations from Veliki Preslav. BULGARIAN E-JOURNAL OF ARCHAEOLOGY, 2(2), 93-121.

Dovramadjiev T. (2017). 3D computer processing and improvement of the geometry of received photogrammetric models through photo shooting with one camera. Proceedings of ISCAME 2017, 12-13 October, 2017 Debrecen, Hungary. ISBN 978-963-473-304-1. p. 115 - 122.

Georgieva I. (1993). Bulgarian National Mythology. II Edition. Science and Art, Sofia, ISBN 95402-0077-6.

Kaufman, J., Rennie, A. E., \& Clement, M. (2015). Single camera photogrammetry for reverse engineering and fabrication of ancient and modern artifacts. Procedia CIRP, 36, 223-229. https://doi.org/10.1016/j.procir.2015.01.073 
Laakso A. (2016). From reality to 3D model. Post production of photogrammetry-based model. LAHTI UNIVERSITY OF APPLIED SCIENCES. a. p. 108

Lobanov A. N. (1984). Photogrammetry. II Edition. Nedra, Moscow. UDK 528.7'(075.8)

Nazarov A. S. (2006). Photogrammetry.TetraSystems. Russia. UDK 528.711 .18 (075.8), BBK 26.12i73; ISBN 985-470-402-5

Obiralov A. I., Limonov A. N., Gavrilova L. A. (2002). Photogrammetry.Koloss.Moscow. UDK 528.7(075.32); ISBN 5-95232-0025-0

Schenk T. (2005). Introduction to Photogrammetry. Autumn Quarter. Department of Civil and Environmental Engineering and Geodetic Science The Ohio State University. GS400.02.

Sirakov N., Demirev V., Ilieva D., Ivanov I. (2014). The Nakit. Regional Historical Museum of Sliven (RIM - Sliven). Museum of NBU (New Bulgarian University). Sofia, ISBN 978-954535-638-5.

Tachev M. (2012). Role of the applied arts in preserving the slavonicidentidy and Bulgarian national idea at the beginning of XX-th century. Work and materials. Moscow, MGU, 21-24.3.2012; ISBN 978-5-211-06356-3

Waas M., Zell D. (2014). Practical 3D photogrammetry for the conservation and documentation of Cultural Heritage.Museen der Stadt Wien - Stadtarchäologie. Proceedings of the 18th International Conference on Cultural Heritage and New Technologies - 2013. ISBN 978-3200-03676-5.

\section{Online sources}

Autodesk MeshMixer software. http://www.meshmixer.com/

Autodesk ReCap software. https://www.autodesk.com/products/recap/overview

Geodetic Systems. Link visited (8.11.2018): https:/www.geodetic.com/v-stars/what-isphotogrammetry/

Iliev I., Kazakova R., Genova M. (2014). Photo Catalog.Histrorical Museum of Dulgopol (IM Dulgopol) . Link visited (26.10.2018): http://www.dalgopol.org/vid2/168.pdf

IQLaser/ Link visited (8.11.2018):

http://www.iqlaser.co.za/files/white_papers/Photogrammetry_basics.pdf

NarodniNosii. (2017). Buckles - an ornament with magical power and special meaning. Link visited (11.11.2018):https://narodninosii.bg/blog/pafti/

NarodniNosii (2018). Nakitiiukrasheniq $\mathrm{v}$ bulgarskitenarodninosii.NarodniNosii. Link visited (26.10.2018): https://narodninosii.bg/blog/nakiti-i-ukrashenia/

Omda. Traditional Bulgarian artistic crafts: Jewelry Belts and buckles. Link visited (11.11.2018): http://www.omda.bg/public/bulg/ethography/belts_buckles_bg.htm 
RIM Shumen. Regional Historical Museum of Shumen. Link visited (11.11.2018): https://museumshumen.eu/пафти/

Topalova R. Regional Historical Museum of Burgas (RIM Burgas). Link visited (3.11.2018):http://www.burgasmuseums.bg/index.php?page=encdetail\&id=152

Uchiteli (2016). Paftite - simvolnajenstvenosttanabulgarkata.Uchiteli. Link visited (26.10.2018):https://uchiteli.bg/interesting/paftite-simvol-na-zhenstvenostta-nabylgarkata/2317 